\title{
Validation of Test-Day Models for Genetic Evaluation of Dairy Goats in Norway
}

\author{
S. Andonov, ${ }^{* 1}$ J. Ødegård,† I. A. Boman,‡ M. Svendsen,§ I. J. Holme,‡ T. Ådnøy,† \\ V. Vukovic,* and G. Klemetsdal† \\ *Faculty of Agricultural Sciences and Food, University Ss Cyril and Methodus, PO Box 297, 1000 Skopje, Macedonia \\ †Department of Animal and Aquacultural Sciences, Norwegian University of Life Sciences (UMB), PO Box 5003, N-1432 Ås, Norway \\ $\ddagger$ The Norwegian Association of Sheep and Goat Breeders (NSG), Norwegian University of Life Sciences (UMB), PO Box 5003, \\ $\mathrm{N}-1432$ Ås, Norway \\ §Geno, Breeding and Al Association, Norwegian University of Life Sciences (UMB), PO Box 5003, N-1432 Ås, Norway
}

\begin{abstract}
Test-day data for daily milk yield and fat, protein, and lactose content were sampled from the years 1988 to 2003 in 17 flocks belonging to 2 genetically welltied buck circles. In total, records from 2,111 to 2,215 goats for content traits and 2,371 goats for daily milk yield were included in the analysis, averaging 2.6 and 4.8 observations per goat for the 2 groups of traits, respectively. The data were analyzed by using 4 testday models with different modeling of fixed effects. Model [0] (the reference model) contained a fixed effect of year-season of kidding with regression on AliSchaeffer polynomials nested within the year-season classes, and a random effect of flock test-day. In model [1], the lactation curve effect from model [0] was replaced by a fixed effect of days in milk (in 3-d periods), the same for all year-seasons of kidding. Models [2] and [3] were obtained from model [1] by removing the fixed year-season of kidding effect and considering the flock test-day effect as either fixed or random, respectively. The models were compared by using 2 criteria: mean-squared error of prediction and a test of bias affecting the genetic trend. The first criterion indicated a preference for model [3], whereas the second criterion preferred model [1]. Mean-squared error of prediction is based on model fit, whereas the second criterion tests the ability of the model to produce unbiased genetic evaluation (i.e., its capability of separating environmental and genetic time trends). Thus, a fixed structure with year (year, year-season, or possibly flock-year) was indicated to appropriately separate time trends. Heritability estimates for daily milk yield and milk content were 0.26 and 0.24 to 0.27 , respectively.
\end{abstract}

Received September 27, 2006.

Accepted June 13, 2007.

${ }^{1}$ Corresponding author: sandonov@zf.ukim.edu.mk
Key words: variance component, milk trait, model validation, test-day model

\section{INTRODUCTION}

In Norway, progeny testing and selection in goat breeding has been for increased milk production, and is currently aimed at improving the quantity of DM per year and goat and the ease of milking (as judged by the person milking). Because one of the main products from goat milk in Norway is a specific goat cheese (Geitost), with lactose being a main component, lactose yield is also included in the breeding goal.

In Norway, cooperative genetic improvement of goats through a buck-circle system was introduced in the 1960s and 1970s. Currently, of the 46,034 recorded goats nationwide (Norwegian; www.ansi.okstate.edu), $42 \%$ participate in 34 circles (Nævdal et al., 2005), carrying out progeny testing on a minimum of 12 daughters per buck (Skipenes, 1996). According to Ådnøy et al. (2000), both young and progeny-tested bucks are circulated across flocks, such that all flocks in a circle use the same bucks. The best progeny-tested young bucks are selected as elite bucks, and mating of these to elite dams gives the possibility of recruiting new buck kids for the following test round. After a second year of use in their original circle, elite bucks may be sold to other circles. In addition, approximately 1,000 doses of frozen semen of 7 to 8 bucks ( 3 to 4 new bucks per year) have been used across circles annually. The bucks used for insemination are chosen from among the best available elite bucks.

The Norwegian Goat Recording System samples data from all flocks participating in milk recording (74\% of all goat flocks in 2004), involving both flocks within and outside the buck-circle system (Vonheim, 2005). Milk recording is required for goats in first and second lactation. Quantity, as a sum of milk in the evening and morning (DMY), is to be recorded at least 5 times per farm and year. Of these monthly re- 
cordings, at least 3 (evening, morning, or both) should include analysis of individual milk content for fat (FC), protein $(\mathbf{P C})$, and lactose $(\mathbf{L C})$ percentages. These data have been used for genetic evaluation by a multitrait animal (BLUP) model, adopted in 1994.

In the genetic evaluation model, the average lactation curve is fitted for each trait, with a fixed AliSchaeffer regression (ASR; Ali and Schaeffer, 1987) nested within combinations of year-season of kidding (December to February, March to May, June to November), 3 regions (north, east, west), and lactation number (1 or 2). The multitrait random effects of flock test-day, as well as additive genetic and permanent environmental effects of each animal are included, in addition to the residual (co)variance components (Ådnøy et al., 2000). The implementation was done by the Norwegian Association of Sheep and Goat Breeders, according to Ptak and Schaeffer (1993).

Since 1994, it has become standard to expand such a model with random regressions (random regression test-day models), allowing, for example, the trajectory of breeding values throughout lactation to be modeled (e.g., Mrode, 2005). In such models, the order of the random regression function can be determined by likelihood-ratio tests, but only for the same fixed effects (e.g., Ødegård et al., 2003). This means that fixed effects have to be determined in advance.

The aim of this study was to develop an alternative to the current model used for genetic evaluation of milk production traits in dairy goats, considering only the contemporary effects (often fixed) structure of the model, by using different criteria. Cross-validation (i.e., comparing the prediction of excluded observations with their observed value as a measure of model fit) may aid in choosing among models. AndersenRanberg et al. (2003a,b) and Ødegård et al. (2003) gained insight by comparing models on the basis of mean-squared error of prediction (MSEP) in crossvalidations. Another criterion is bias of prediction, meaning that genetic predictions relying on new information should, on average, not change compared with the first. According to Andersen-Ranberg et al. (2003b), animal models can preferably be examined for potential bias by using the second method of Boichard et al. (1995), which checks whether the year of birth of the daughters of a sire affects their contribution to the sire's breeding value prediction.

\section{MATERIALS AND METHODS}

\section{Data}

The data used in this analysis were extracted from the data set used in genetic evaluation in November
Table 1. Descriptive statistics of the data set from 17 flocks

\begin{tabular}{lcccc}
\hline Trait & Records, $\mathrm{n}$ & Goats, $\mathrm{n}$ & Average & SD \\
\hline Daily milk yield, $\mathrm{kg}$ & 11,438 & 2,371 & 1.67 & 0.59 \\
Fat content, \% & 5,896 & 2,215 & 3.88 & 0.87 \\
Protein content, \% & 5,896 & 2,215 & 2.78 & 0.33 \\
Lactose content, \% & 5,686 & 2,111 & 4.44 & 0.29 \\
\hline
\end{tabular}

2003. The data for DMY, FC, PC, and LC were from the years 1988 to 2003 . Test-day data of single goats from 5 to 305 DIM were kept when ranging from 0.1 to $9.9 \mathrm{~kg}$ of DMY, whereas values of between 1 and 9\% were accepted for milk composition (FC, PC, LC). For each goat, year and season of kidding were identified (December to February, March to May, and June to November) in accordance with current practice in genetic evaluation. Because most flocks have only one kidding season per year and it is general practice to remove kids from their mothers at birth, it was assumed to be redundant to model any effect of the number of kids on milk production.

To reduce the computational burden, further restrictions were imposed for this study. First, data were restricted to primiparous goats only. Second, only data from 2 well-tied buck circles (17 flocks) within one region (Hedmark) were used. For these buck circles, $19 \%$ of the bucks had daughters in both circles, constituting $37 \%$ of the goats. Data from flocks in the region outside the buck-circle system were not included in this analysis. Descriptive statistics of the data are presented in Table 1.

The pedigree data contained all animals with records from flocks both within and outside the buckcircle system, as well as their ancestors, traced back as far as possible. In total, the pedigree contained 5,511 animals (421 sires and 5,090 dams). Among these, 261 animals defined the base population.

\section{Models}

The aim of the study was to improve the modeling of the contemporary (often fixed) structure of the model used in current genetic evaluation, defined as the model of reference [0]:

$$
\begin{gathered}
Y_{i j k}=Y S_{i}+b_{1 i}\left(\frac{D I M}{305}\right)+b_{2 i}\left(\frac{D I M}{305}\right)^{2} \\
+b_{3 i} \ln \left(\frac{305}{D I M}\right)+f t d_{j}+a_{k}+p e_{k}+e_{i j k}
\end{gathered}
$$

where $Y_{i j k}$ is DMY, FC, PC, or LC for goat $k$ within year-season of kidding $i$ in flock test-day $j ; Y S_{i}$ is the fixed year-season of kidding effect, with 3 levels in 
Table 2. Fixed (F) and random (R) effects, specified in the 4 test-day models used to analyze milk production traits

\begin{tabular}{|c|c|c|c|c|c|c|}
\hline Model & $\begin{array}{l}\text { Year-season } \\
\text { of kidding }\end{array}$ & $\begin{array}{l}\text { Ali-Schaeffer } \\
\text { regression } \\
\text { within } \\
\text { year-season } \\
\text { of kidding }\end{array}$ & DIM $^{1}$ & $\begin{array}{l}\text { Flock } \\
\text { test-day }\end{array}$ & Animal & $\begin{array}{l}\text { Permanent } \\
\text { environment }\end{array}$ \\
\hline 0 & $\mathrm{~F}$ & $\mathrm{~F}$ & - & $\mathrm{R}$ & $\mathrm{R}$ & $\mathrm{R}$ \\
\hline 1 & $\mathrm{~F}$ & - & $\mathrm{F}$ & $\mathrm{R}$ & $\mathrm{R}$ & $\mathrm{R}$ \\
\hline 2 & - & - & $\mathrm{F}$ & $\mathrm{F}$ & $\mathrm{R}$ & $\mathrm{R}$ \\
\hline 3 & - & - & $\mathrm{F}$ & $\mathrm{R}$ & $\mathrm{R}$ & $\mathrm{R}$ \\
\hline
\end{tabular}

${ }^{1}$ Three-day periods.

each of $16 \mathrm{yr} ; b_{1 i}, b_{2 i}$, and $b_{3 i}$ are modified ASR, nested within year-season of kidding classes; $f t d_{j}$ is the random effect of flock test-day; $a_{k}$ is the random animal genetic effect; and $p e_{k}$ and $e_{i j k}$ are random effects of the permanent environment of the animal and residual, respectively.

A simpler model is one with a joint lactation curve for all year-seasons of kidding, modeled as a fixed effect of stage of lactation, defined in 3-d intervals starting from d $5\left(D I M 3_{l}\right.$, where $\left.l=1, \ldots, 101\right)$, resulting in model [1]:

$$
Y_{i j k l}=Y S_{i}+D I M 3_{l}+f t d_{j}+a_{k}+p e_{k}+e_{i j k l} .
$$

In models [0] and [1], $Y S_{i}$ has the potential to account for environmental trends over time. However, because the average numbers of observations per flock testday were around 14 (close to the lower limit of 15 for contemporary groups to be recommended, modeled as a fixed effect; van Bebber et al., 1997), another specification capable of accounting for time trends was considered by omitting $Y S_{i}$ and considering flock test-day as fixed $\left(F T D_{j}\right)$, giving model [2]:

$$
Y_{j k l}=D I M 3_{l}+F T D_{j}+a_{k}+p e_{k}+e_{j k l} .
$$

Finally, flock test-day was considered as random, whereas $Y S_{i}$ was still omitted, defining model [3]:

$$
Y_{j k l}=D I M 3_{l}+f t d_{j}+a_{k}+p e_{k}+e_{j k l}
$$

that is, a model with no fixed effect capable of accounting for trends over the years.

An overview of the effects specified in the 4 models used is given in Table 2. The number of classes for fixed effects and the average number of records per subclass and trait are shown in Table 3. Because DMY was recorded more frequently than milk content in a flock-intentionally, 5 and 3 times a year, respectively-the number of observations per level of yearseason of kidding or DIM was higher for DMY than for FC, PC, and LC, but was still with a similar average number of records per level of flock test-day.

In all models, homogeneous residual variances were assumed. Variance analyses were carried out one trait at a time by using REML techniques with the software package VCE, version 5.1.2 (Kovač and Groeneveld, 2003). The breeding value predictions were carried out by PEST software, version 4.2.1 (Groeneveld, 1990).

\section{Model Comparison}

A comparison of model [0] and model [1] demonstrates whether the ASR, when used within $Y S$, gives a better evaluation than a fixed common lactation curve over the years. The fixed FTD of model [2] includes the fixed YS effects of models [0] and [1]. Model [3] has no fixed effect to account for changes over the years and may be contrasted with model [1]. The models were compared by using 2 criteria: 1) MSEP for excluded observations, and 2) a test of bias affecting the genetic trend, according to the second method of Boichard et al. (1995).

Mean-squared error of prediction was calculated by randomly excluding $5 \%$ of the observations while keeping at least one record per animal, and by predicting those observations based on the remaining data set. To reduce sampling error, 6 different subsamples were created, and predictive ability was estimated as the average over subsamples, according to:

$$
M S E P=\left[\sum_{i=1}^{6}\left(\frac{1}{n} \sum_{j=1}^{n}\left(y_{j}-\hat{y}_{j}\right)^{2}\right)\right] / 6,
$$

where $y_{j}$ is one of $n$ excluded observations, and $\hat{y}_{j}$ is the predicted value of that observation, based on the remaining data set. Variance components estimated from the same model using the entire data set were used as true parameters in the prediction of excluded observations. 
Table 3. Number of levels (average number of records) for year-season of kidding, DIM, and flock test-day for daily milk yield (DMY), fat content (FC), protein content (PC), and lactose content (LC) ${ }^{1}$

\begin{tabular}{lcrrr}
\hline Effect & DMY & \multicolumn{1}{c}{ FC } & \multicolumn{1}{c}{ PC } & \multicolumn{1}{c}{ LC } \\
\hline Year-season of kidding & $42(272.3)$ & $41(143.8)$ & $41(143.8)$ & $34(167.2)$ \\
DIM $^{2}$ & $101(113.3)$ & $101(58.4)$ & $101(58.4)$ & $101(56.3)$ \\
Flock test-day & $786(14.6)$ & $428(13.8)$ & $428(13.8)$ & $403(14.1)$ \\
\hline
\end{tabular}

${ }^{1}$ Primiparous goats only.

${ }^{2}$ Three-day periods.

Bias affecting the genetic trend was tested by using the following model described by Boichard et al. (1995):

$$
d_{i j k}=s_{i}+t_{m}+e_{i j k}
$$

where $d_{i j k}$ is the average daughter deviation of daughter $k$ of sire $i$ obtained in year $j, s_{i}$ is a fixed effect of sire $i, t_{m}$ is a fixed effect of the year $m$ of use of sire $i$, and $e_{i j k}$ is a random error term. Year of use was defined as $m=j-j_{0}+1$, where $j$ is as described, and $j_{0}$ is the year of first yield of the first daughter of sire $i$. Normally, test bucks are used in one mating season, but selected bucks will have daughters in more than one year and will serve to check changes in average predicted breeding values.

\section{RESULTS AND DISCUSSION}

Phenotypic trends over the years for all traits are shown in Figure 1. The trend for FC was upward, whereas the changes for DMY, PC, and LC were smaller over time. Results for the estimated variance
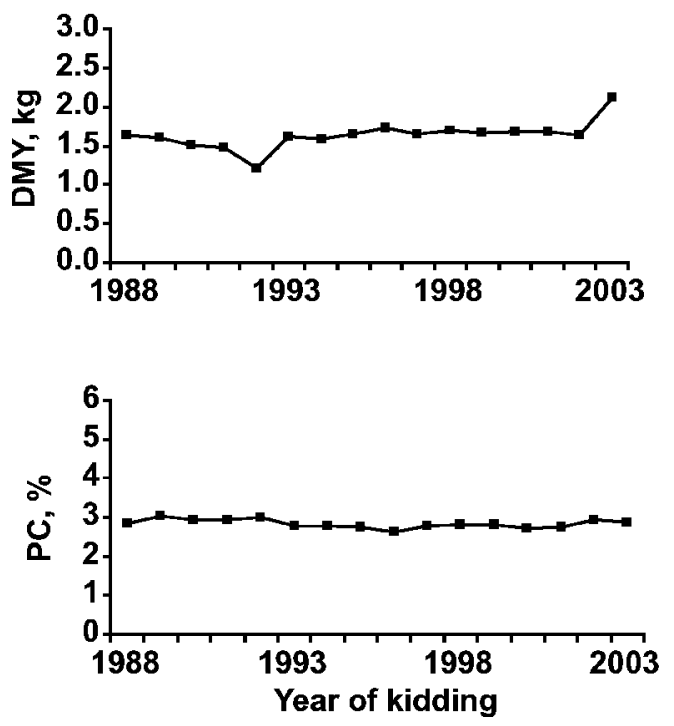

components and MSEP under the 4 models are shown in Table 4. For all traits, models [0] and [1] produced very similar variance components, but MSEP values were always lower with model [1]. Thus, ASR nested within $Y S$, allowing different lactation curves for all years and seasons, was no better than modeling the same 3 -d periods (101 classes for DIM, with the numbers of observations per subclass varying in size from 56.3 to 113.3) in all years. However, the ASR gives great flexibility for few estimated effects. A competing alternative would be to model the lactation curve across years by using ASR, but demanding 9 estimated parameters. Furthermore, caution should be shown in generalizing the result to an analysis with more data; the nested ASR (having the largest number of parameters) may gain relatively more from the increasing number of records.

Model [1] and model [0] contained the YS effect with the capability of taking out the time trend. In model [2], a fixed effect of flock test-day (FTD) was included for the same purpose (YS omitted), but, according to MSEP, this model did not improve the predictive ability compared with model [1] or model [0] for any of
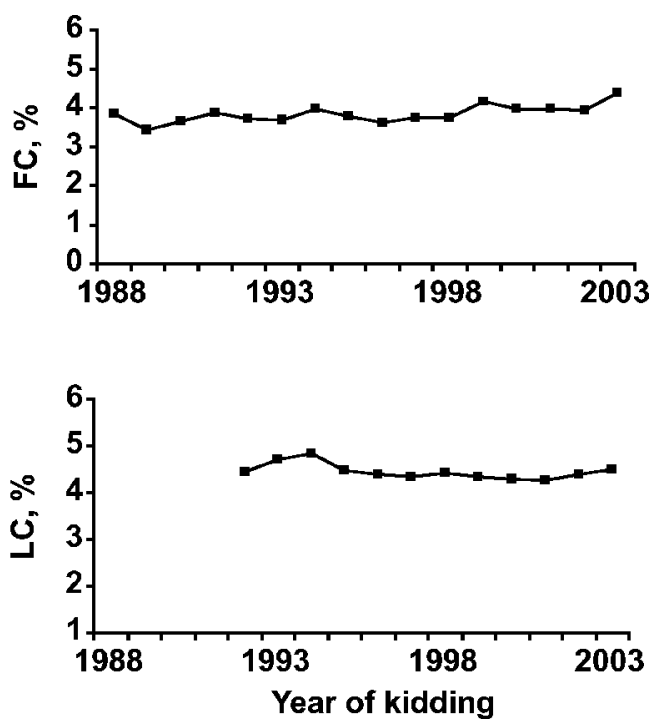

Figure 1. Phenotypic trends of daily milk yield (DMY), fat content (FC), protein content (PC), and lactose content (LC). 
Table 4. Estimated animal additive genetic $\left(\sigma_{\mathrm{a}}^{2}\right)$, flock-test day $\left(\sigma_{\mathrm{ftd}}^{2}\right)$, permanent environmental $\left(\sigma_{\mathrm{pe}}^{2}\right)$ and residual $\left(\sigma_{\mathrm{e}}^{2}\right)$ variances, heritability, ${ }^{1}$ and mean-squared error of prediction (MSEP) for daily milk yield (DMY), fat content (FC), protein content (PC), and lactose content (LC), estimated with 4 different test-day models $^{2}$

\begin{tabular}{lcccccc}
\hline Item & $\sigma_{\mathrm{a}}^{2}$ & $\sigma_{\mathrm{ftd}}^{2}$ & $\sigma_{\mathrm{pe}}^{2}$ & $\sigma_{\mathrm{e}}^{2}$ & $\mathrm{~h}^{2}$ & MSEP \\
\hline DMY & & & & & & \\
Model [0] & 0.0448 & 0.0885 & 0.0539 & 0.0690 & 0.2671 & 0.8848 \\
Model [1] & 0.0439 & 0.0991 & 0.0543 & 0.0701 & 0.2607 & 0.8530 \\
Model [2] & 0.0285 & - & 0.0632 & 0.0700 & 0.1763 & 1.0484 \\
Model [3] & 0.0492 & 0.1016 & 0.0522 & 0.0702 & 0.2870 & 0.7511 \\
FC & & & & & & \\
Model [0] & 0.1078 & 0.2464 & 0.0582 & 0.2887 & 0.2371 & 0.4758 \\
Model [1] & 0.1080 & 0.2419 & 0.0575 & 0.2889 & 0.2376 & 0.4733 \\
Model [2] & 0.0912 & - & 0.0677 & 0.2893 & 0.2036 & 0.5364 \\
Model [3] & 0.1073 & 0.2495 & 0.0587 & 0.2891 & 0.2357 & 0.4733 \\
PC & & & & & & \\
Model [0] & 0.0159 & 0.0193 & 0.0086 & 0.0333 & 0.2748 & 0.6047 \\
Model [1] & 0.0167 & 0.0197 & 0.0085 & 0.0360 & 0.2733 & 0.5890 \\
Model [2] & 0.0159 & - & 0.0090 & 0.0358 & 0.2621 & 0.6610 \\
Model [3] & 0.0179 & 0.0239 & 0.0082 & 0.0359 & 0.2888 & 0.6041 \\
LC & & & & & & \\
Model [0] & 0.0099 & 0.0072 & 0.0078 & 0.0166 & 0.2884 & 0.3678 \\
Model [1] & 0.0095 & 0.0085 & 0.0081 & 0.0170 & 0.2747 & 0.3363 \\
Model [2] & 0.0098 & - & 0.0075 & 0.0168 & 0.2878 & 0.5104 \\
Model [3] & 0.0126 & 0.0276 & 0.0064 & 0.0167 & 0.3520 & 0.3328 \\
\hline
\end{tabular}

${ }^{1} h^{2}=\frac{\sigma_{a}^{2}}{\sigma_{a}^{2}+\sigma_{p e}^{2}+\sigma_{e}^{2}}$.

${ }^{2}$ As specified in Table 2 .

the traits (Table 4). In model [2] (except for LC), the additive genetic variance was lower than in model [1] or model [0] (Table 4), showing that the fixed flock test-day effects tended to absorb the genetic effects. Furthermore, with less variance being determined as additive genetic, the permanent environmental variance of animal was allowed to increase (Table 4). It is possible that more of the additive genetic variance would be obtained from improved modeling, replacing the fixed flock test-day effect by a fixed effect of flockyear and a random effect of flock test-day, considerably increasing the number of observations per fixed effect subclass.

In model [3], there was no fixed effect to model trend over the years. The estimated additive genetic variances with model [3] were higher than those for other models (except for FC), as were the flock test-day variances, indicating increased variances from time trends (Table 4). Consequently, the enlarged additive genetic variance reduced the variance component estimate of the permanent environment of the individual animal (Table 4). Model [3] gave the least MSEP for DMY, $\mathrm{FC}$, and LC of all tested models (but not for PC).

Hence, the results from evaluating the models on MSEP suggest choosing model [3]. However, this model tended to increase the additive genetic variances, most likely from a time trend, which would affect the genetic trend. Hence, further comparison of the genetic trends in models [3] and [1] (with the latter capable of accounting for an environmental time trend through the fixed $Y S$ effect) was required.

Genetic trends for DMY, FC, PC, and LC obtained with either model [1] or model [3] are shown in Figure 2. A rather large year-to-year variation in average breeding values was found. With only 17 flocks, and a limited number of bucks used each year, the finite number of animals may have caused this result. For each trait, the 2 models produced trends in the same direction but with a different steepness to the curves, motivating us to test for bias in genetic prediction.

To formally test the models for bias in genetic prediction, daughter deviations of bucks were analyzed for the fixed effects of sire and year of use of sire by ANOVA, following Boichard et al. (1995). The year of use effect should not be significantly different from zero if the genetic prediction of bucks is unbiased. The results of the ANOVA are summarized in Table 5. A significant bias $(P \leq 0.0479)$ was found only for $\mathrm{FC}$ with model [3]. However, when we used the $F$-statistic for year of use of sire to choose between the models, the estimated bias for model [3] was larger for all traits than for model [1], giving preference to model [1]. The estimated effect of year of use of buck is plotted in Figure 3 . With $90 \%$ of the year of use values ranging from 

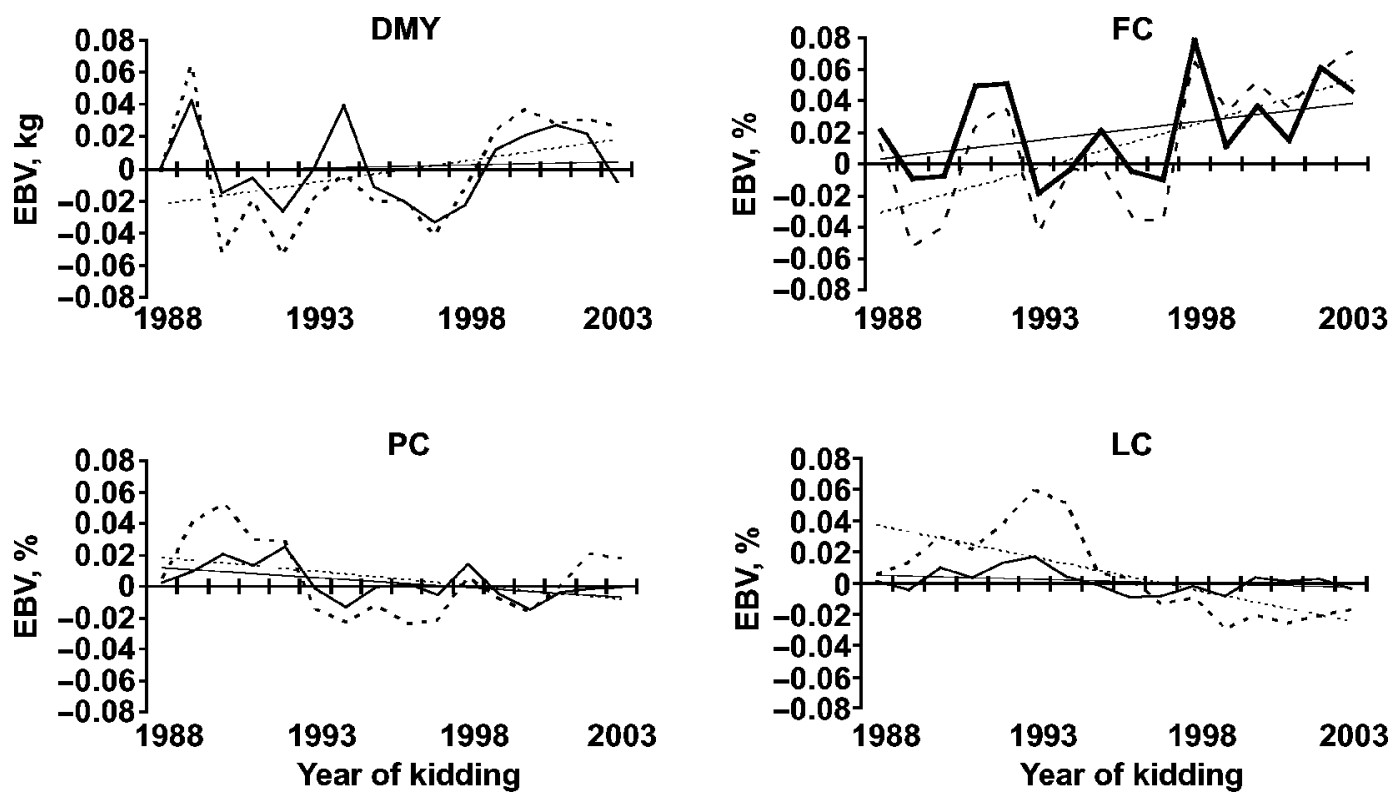

Figure 2. Genetic trends for daily milk yield (DMY), fat content (FC), protein content (PC), and lactose content (LC) plotted as average EBV per year of kidding, and their simple linear regressions, for model [1] (solid lines) and model [3] (dotted lines), the 2 models specified in Table 2 .

1 to 3 , and only considering these years, model [3] deviations were larger than model [1] deviations for DMY and FC, whereas only minor differences between models were seen for PC and LC. Thus, model validation with the second method of Boichard et al. (1995) preferred model [1], in contrast to the MSEP, which favored model [3]. A fixed structure for modeling year or year-season effects seems to be appropriate to separate genetic and environmental time trends. This is in accordance with Visscher and Goddard (1993).
Figure 4 shows the environmental trend, modeled by the YS solutions in model [1]. The simple linear regression slopes for DMY, FC, and LC were significant $(P<0.01,0.05$, and 0.0001 , respectively) — upward for DMY and FC and downward for LC-but there was no significant slope for PC. The solutions for DIM3 in model [1] are shown in Figure 5, describing the lactation curve for DMY, FC, PC, and LC.

For the chosen model (model [1]), heritability estimates for DMY, FC, PC, and LC were 0.24 to 0.27 ,

Table 5. Results of the method 2 test of bias of Boichard et al. (1995), based on ANOVA of daughter deviations for daily milk yield (DMY), fat content (FC), protein content (PC), and lactose content (LC) from 2 models, ${ }^{1}$ equated to sire ( $\mathrm{s}$ ) and year of use of sire (t) as fixed explanatory variables, while the residual effect (e) is random ${ }^{2}$

\begin{tabular}{|c|c|c|c|c|c|c|c|c|c|}
\hline \multirow[b]{2}{*}{ Item } & \multirow[b]{2}{*}{ Source } & \multicolumn{4}{|c|}{ Model [1] } & \multicolumn{4}{|c|}{ Model [3] } \\
\hline & & $\mathrm{df}$ & MS & $F$ & $P$ & $\mathrm{df}$ & MS & $F$ & $P$ \\
\hline \multirow[t]{3}{*}{ DMY } & $\mathrm{s}$ & 224 & 0.0669 & 7.0205 & 0.0000 & 224 & 0.0759 & 6.5412 & 0.0000 \\
\hline & $\mathrm{t}$ & 4 & 0.0042 & 0.4369 & 0.7820 & 4 & 0.0111 & 0.9576 & 0.4297 \\
\hline & $\mathrm{e}$ & 1,858 & 0.0095 & & & 1,858 & 0.0116 & & \\
\hline \multirow[t]{3}{*}{$\mathrm{FC}$} & $\mathrm{s}$ & 224 & 0.0193 & 7.6712 & 0.0000 & 224 & 0.0185 & 2.4415 & 0.0000 \\
\hline & $\mathrm{t}$ & 4 & 0.0029 & 1.1695 & 0.3224 & 4 & 0.0182 & 2.4029 & 0.0479 \\
\hline & $\mathrm{e}$ & 1,858 & 0.0025 & & & 1,858 & 0.0076 & & \\
\hline \multirow[t]{3}{*}{$\mathrm{PC}$} & $\mathrm{s}$ & 224 & 0.0268 & 5.4976 & 0.0000 & 224 & 0.0237 & 5.3921 & 0.0000 \\
\hline & $\mathrm{t}$ & 4 & 0.0027 & 0.5579 & 0.6932 & 4 & 0.0037 & 0.8441 & 0.4971 \\
\hline & $\mathrm{e}$ & 1,858 & 0.0049 & & & 1,858 & 0.0044 & & \\
\hline \multirow[t]{3}{*}{$\mathrm{LC}$} & $\mathrm{s}$ & 224 & 0.0123 & 5.3470 & 0.0000 & 224 & 0.0243 & 6.6973 & 0.0000 \\
\hline & $\mathrm{t}$ & 4 & 0.0021 & 0.9185 & 0.4522 & 4 & 0.0042 & 1.1511 & 0.3307 \\
\hline & $\mathrm{e}$ & 1,858 & 0.0023 & & & 1,858 & 0.0036 & & \\
\hline
\end{tabular}

\footnotetext{
${ }^{1}$ As specified in Table 2 .

${ }^{2} \mathrm{~A}$ significant effect of $\mathrm{t}$ indicates a bias in genetic evaluation.
} 

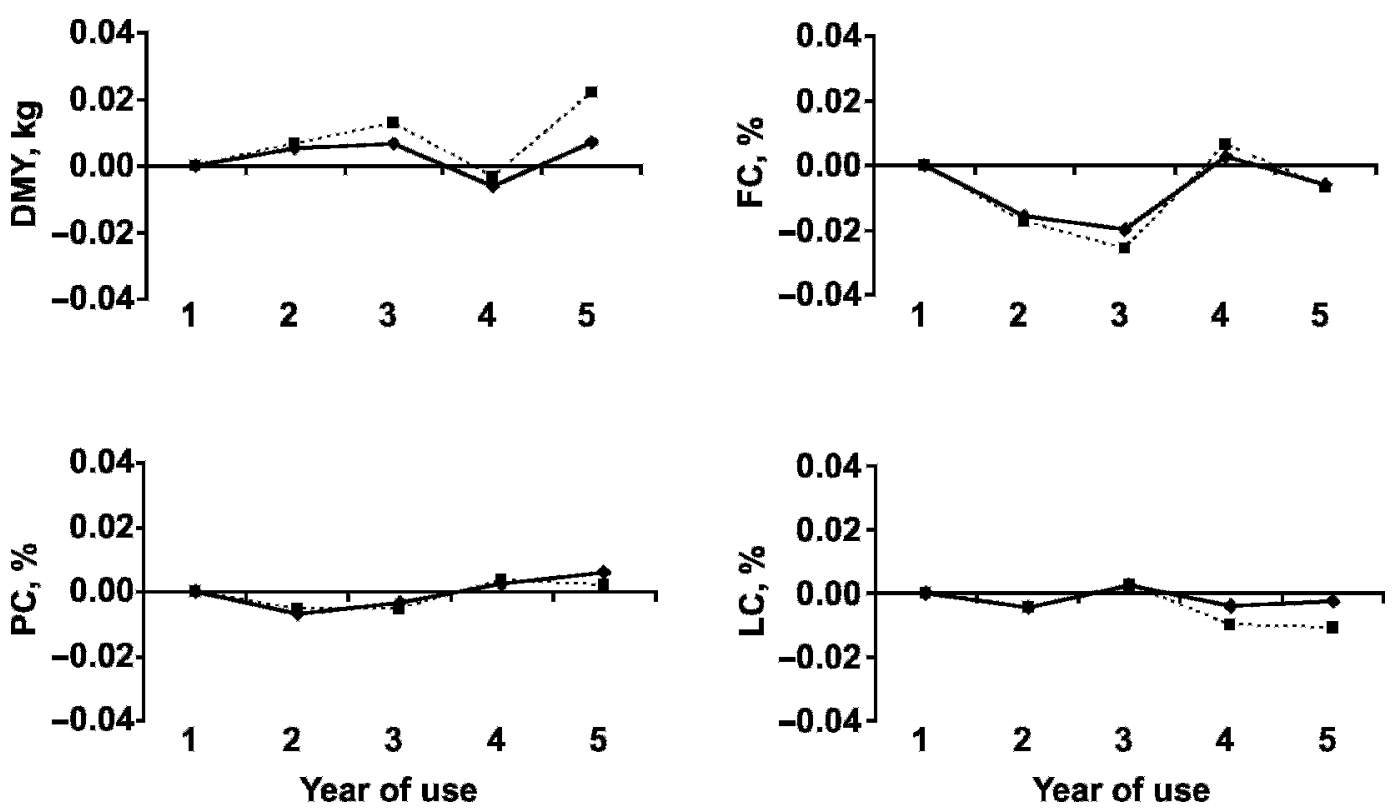

Figure 3. Solutions for the bucks' year of use (as deviations from the first year) for daughter deviations for daily milk yield (DMY), fat content (FC), protein content (PC), and lactose content (LC) from model [1] (solid lines) and model [3] (dotted lines), the 2 models specified in Table 2.

similar to the study by Schaeffer and Sullivan (1994; Table 4). However, our findings were generally within the literature ranges obtained with test-day models (higher than Andonov, 1994; Portolano et al., 2001; Weppert and Hayes, 2004; and lower than Concavales and Wechsler, 2000).
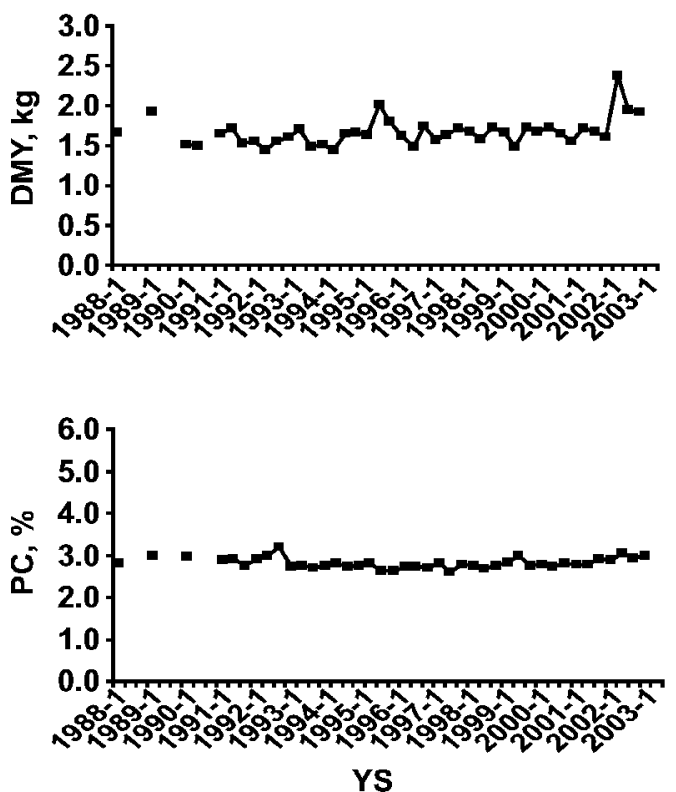

For these 2 buck circles, and by using the chosen model [1], significant upward genetic change was found for DMY and FC $(P<0.042$ and $P<0.004$, respectively). A significant negative genetic change was obtained for LC $(P<0.014)$, whereas the downward trend for PC was not significant $(P<0.0643)$. Whether this
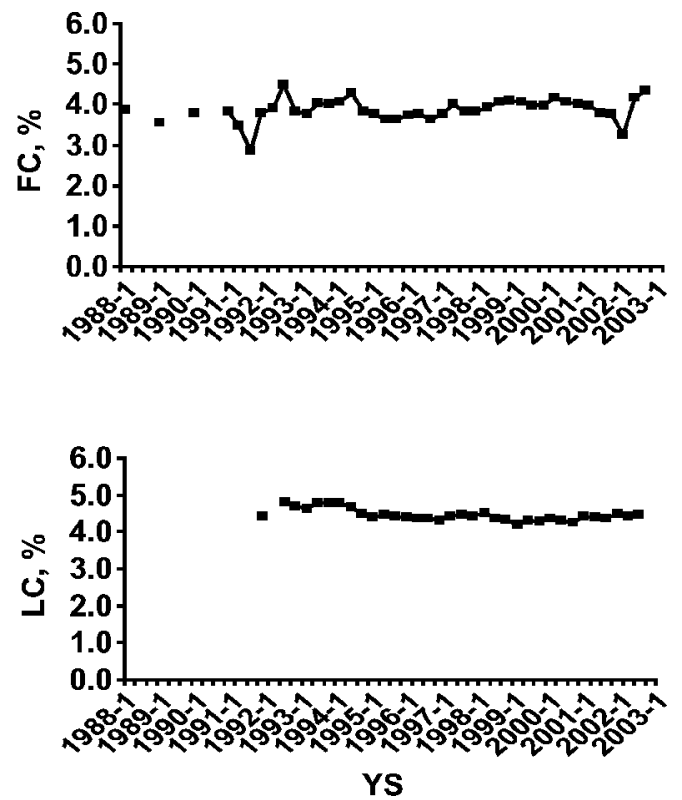

Figure 4. Solutions (including the population average) of year-season of kidding effect (YS) for daily milk yield (DMY), fat content (FC), protein content (PC), and lactose content (LC) from model [1], as specified in Table 2. 

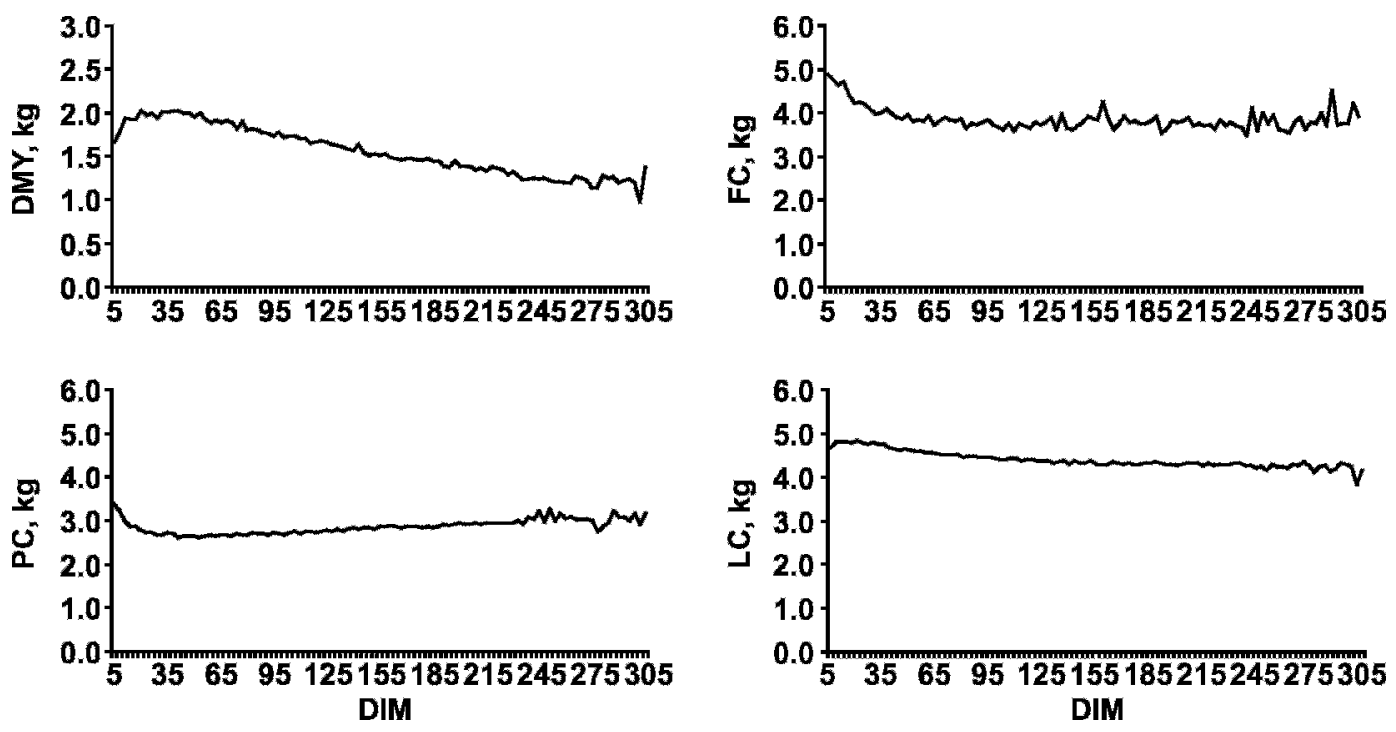

Figure 5. Solutions (including the population average) of DIM, in 3-d intervals, for daily milk yield (DMY), fat content (FC), protein content (PC), and lactose content (LC) from model [1], as specified in Table 2.

is the general pattern for other buck circles needs to be evaluated. Ådnøy et al. (2004) compared the production of offspring of AI bucks from around 1980 with offspring of contemporary AI bucks. They found an increase for LC and total DM of milk, but not for PC or FC.

\section{CONCLUSIONS}

This study gave preference to an animal model that included a fixed structure with year (year, year-season, or possibly flock-year) and a random effect of flock test-day (model [1]) in the genetic analysis of DMY and milk content in primiparous dairy goats from buck circles in Norway. This is similar to effects actually included in the model used for genetic evaluation in the Norwegian goat-breeding scheme. The second method of Boichard et al. (1995) was found to discriminate between candidate models. Heritability estimates for DMY and milk content were 0.26 and 0.24 to 0.27 , respectively. These high estimates may indicate small random errors in observations of test-day records for goats in Norway.

\section{ACKNOWLEDGMENTS}

The study was funded by the Norwegian Research Council, fellowship program IS SOE 03/04-41. Access to the data was given by Tine BA in agreement 001.2004. The Norwegian Association of Sheep and Goat Breeders covered some travel expenses.

\section{REFERENCES}

Ådnøy, T., I. Nævdal, and M. Svendsen. 2000. Buck circles for dairy goat breeding in Norway. Page 1049 in Proc. 7th Int. Conf. Goats, Tours, France. Institut de l'Elevage, Paris, France.

Ådnøy, T., T. Tilahun, M. Eknes, and L. O. Eik. 2004. Goat breeding program has changed milk production potential in Norway. Page 13 in Proc. 8th Int. Conf. Goats, Pretoria, South Africa.

Ali, T. E., and L. R. Schaeffer. 1987. Accounting for covariances among test-day milk yields in dairy cows. Can. J. Anim. Sci. 67:637-644.

Andersen-Ranberg, I. M., B. Heringstad, G. Klemetsdal, M. Svendsen, and T. Steine. 2003a. Heifer fertility in Norwegian dairy cattle: Variance components and genetic change. J. Dairy Sci. 86:2706-2714.

Andersen-Ranberg, I. M., G. Klemetsdal, and B. Heringstad. 2003b. Short communication: Validation of two animal models for estimation of genetic trends for female fertility in Norwegian dairy cattle. J. Dairy Sci. 86:4090-4092.

Andonov, S. 1994. Estimation of genetic parameters for milk production in dairy goats using the first records of lactation. MSc Thesis. University of Ljubljana, Slovenia.

Boichard, D., B. Bonati, A. Barbat, and S. Mattalia. 1995. Three methods to validate the estimation of genetic trend for dairy cattle. J. Dairy Sci. 78:431-437.

Concavales, H. C., and F. S. Wechsler. 2000. Genetic and environmental factors affecting milk production of dairy goats in Brazil. Page 240 in Proc. 7th Int. Conf. Goats, Tours, France. Institut de l'Elevage, Paris, France

Groeneveld, E. 1990. Pest User's Manual. FAL, Neustadt, Germany.

Kovač, M., and E. Groeneveld. 2003. VCE 5 User's Guide and Reference Manual. University of Ljubljana, Slovenia.

Mrode, R. A. 2005. Linear Models in the Prediction of Animal Breeding Values. 2nd ed. CABI Publishing, Oxfordshire, UK.

Nævdal, I., A. Lohn, V. Fagerland, T. Ảnøy, H. Paulenz, and E. Wallin. 2005. Fagrapport 2004. Geitavl. Avlsrådet for geit. Fagforum geit. NSG. Oslo, Norway. (In Norwegian)

Ødegård, J., J. Jensen, G. Klemetsdal, P. Madsen, and B. Heringstad. 2003. Genetic analyses of somatic cell score in Norwegian cattle using random regression test-day models. J. Dairy Sci. 86:4103-4114. 
Portolano, B., L. Montalbano, and W. Militi. 2001. Genetic and environmental sources of variation for milk yield traits in Barbaresca siciliana breed. Small Rumin. Res. 41:195-202.

Ptak, E., and L. R. Schaeffer. 1993. Use of test day yields for genetic evaluation of dairy sires and cows. Livest. Prod. Sci. 34:23-34.

Schaeffer, L. R., and B. P. Sullivan. 1994. Genetic evaluation of dairy goats using test day yields. Proc. 4th World Congr. Genet. Appl. Livest. Prod. 18:182-185.

Skipenes, P. 1996. Nytt indekssystem tatt i bruk i geitavlen. Sau og Geit. 1:10-11. (In Norwegian) van Bebber, J., N. Reinsch, W. Junge, and E. Kalm. 1997. Accounting for herd, year and season effects in genetic evaluations of dairy cattle: A review. Livest. Prod. Sci. 51:191-203.

Visscher, P. M., and M. E. Goddard. 1993. Fixed and random contemporary groups. J. Dairy Sci. 76:1444-1454.

Vonheim, V. 2005. Nøkkeltall for geitekontrollen 2004. Tine BA, Ås, Norway. (In Norwegian)

Weppert, M., and J. F. Hayes. 2004. Direct and maternal genetic influence on first lactation production in four breeds of dairy goats. Small Rumin. Res. 52:173-178. 